\title{
Endüstriyel odundaki sürütme zararlarının hasat mevsimine göre karşılaştırılması
}

\author{
Comparison of skidding damages to industrial woods in terms of harvesting seasons
}

\author{
Saliha ÜNVER OKAN ${ }^{i D}$, Selçuk GÜMÜş ${ }^{i}$ \\ Karadeniz Teknik Üniversitesi Orman Fakültesi Orman Mühendisliği Bölümü, Trabzon Türkiye
}

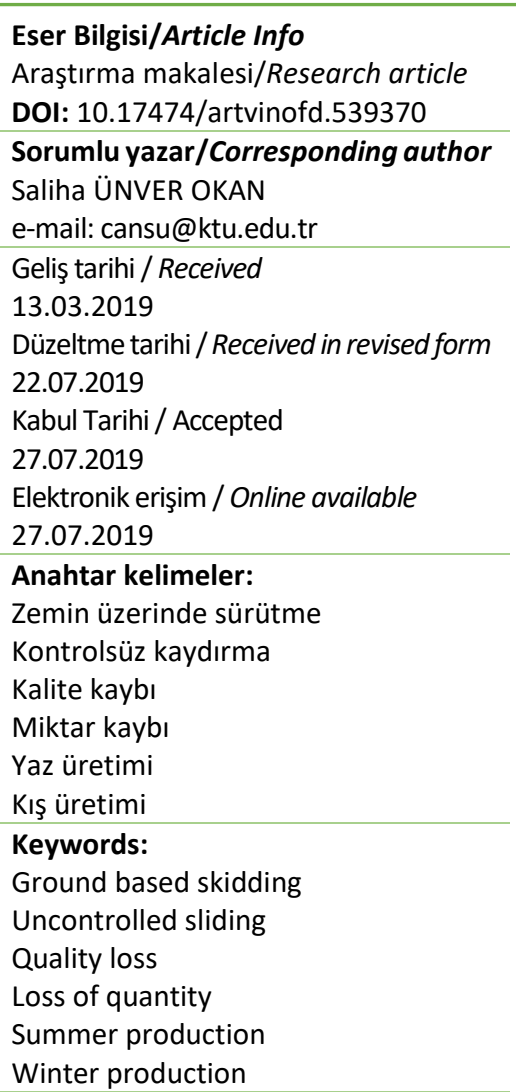

\begin{abstract}
Özet
Dünyada çok sayıda kullanım alanı olan odun hammaddesinin değerinin belirlenmesinde dikkate alınan ana parametreler; ürünün vasfı (tomruk, direklik, sanayi odunu ya da yakacak odun gibi), kalite sınıfı ve miktarıdır. Odun hammaddesinin vasfına ve kalite sınıfına göre birim fiyatlarının farklı olması nedeniyle ürünlerin değerleri de önemli oranda değişir. Ülkemizde mevcut orman yollarının standartlarının uygun olmaması ve mekanizasyonun fazla gelişmemiş olması nedeniyle büyük oranda tomruk üretimi yapılmakta ve zemin üzerinde kaydırma/sürütme teknikleri kullanılmaktadır. Bu çalışmanın amacı, eğimli ormanlarda yukarıdan aşağıya doğru kontrolsüz kaydırma ile gerçekleştirilen bölmeden çıkarma çalışmalarında tomruklarda oluşan kalite ve miktar kayıplarının hasat mevsimine göre farklılık gösterip göstermediğinin karşılaştırılmasıdır. Çalışma, Doğu Karadeniz Bölgesinde yarısı yaz mevsiminde ve yarısı kış mevsiminde zemin üzerinde kaydırma tekniği uygulanan toplam on altı adet hasat biriminde gerçekleştirilmiştir. Çalışma kapsamında kaydırma faaliyetlerinden önce ve sonra; tomrukların kalite sınıfları belirlenmiş, çap ve boyları ölçülmüş ve hacimleri hesaplanmıştır. Ayrıca sürütme sonrasında odunlarda meydana gelen kırılma, çatlama, saçaklanma ve yaralanma gibi zarar tipleri ve zararların tomruk üzerindeki yeri tespit edilmiş, zararların boyutları ölçülmüştür. Kış mevsiminde tomruklarda oluşan zararlar yaz mevsimine oranla belirgin olarak daha az bulunmuştur. Yapılan bağımsız örneklem $t$ testi analizinde hasat mevsimi ile zararın yeri, tipi ve odunun boyu arasında \%95 güven düzeyinde $(\mathrm{P}<0.05)$ bir fark olduğu belirlenmiştir. Yaz mevsiminde özellikle tomrukların uç kısımlarında oluşan zararları azaltmak için tomruk başlarına polietilen tomruk konisi takılması uygun olacaktır. Özellikle zeminin engebeli olduğu durumlarda gövde üzerindeki zararların önüne geçmek için yapay bir güzergah üzerinde kontrollü sürütme tekniği ya da havai sistemler kullanılmalıdır.
\end{abstract}

\begin{abstract}
The main parameters which are taken into consideration are the type (such as timber, pole or firewood), quality and quantity of the product in determining the value of wood. Since the unit prices are different according to the type and quality class of wood, the values of the products also change significantly. The log production in Turkey is carried out due to insufficient mechanization and inappropriate of the standards of existing forest roads. The ground based skidding techniques are largely used during the extraction of the logs. The aim of this study is to determine whether the damages on logs caused by uncontrolled ground based skidding/sliding downhill vary according to harvest season. The study was conducted applied ground based skidding in summer and winter seasons in total sixteen harvesting units in the Eastern Black Sea Region. Within the scope of the study; the quality classes, diameters and lengths of the logs were determined, and volumes of logs were calculated. It was determined that the types (such as fracture, cracking, fringing and injury) and locations of damages that occured on logs after ground based skidding. In the winter season, the damages on the logs were significantly less than in the summer season. In the independent sample $t$ test analysis, it was determined that there was a difference in the $95 \%$ confidence level $(P<0.05)$ between the harvest seasons and the location of damage, type of damage and length of the logs. In order to reduce the damages on the ends of the logs Especially in the summer season, it is appropriate to fit the polyethylene log cones on log heads. Especially in rough areas, cable yarding systems or controlled skidding on an artificial route by a motor power or reel system can be used to reduce damage on logs.
\end{abstract}

\section{GiRiş}

Ormanlar geçmişten günümüze her zaman ekonomik, ekolojik ve sosyal fonksiyonları olan canlı ve büyük ekosistemlerdir. Ormanların başlıca ekonomik fonksiyonu toplumun ihtiyaç duyduğu mal ve hizmetleri karşılayarak ormancılık sektörüne gelir sağlamadır. Ormancılıkta mal üretimi, ekonomik değeri olan ve pek çok endüstri koluna hammadde sağlayan orman ürünlerinin, ulusal ve uluslararası ekonomideki gereksinimlerini karşılama işlevi 
olarak tanımlanır (Kazancıoğlu ve ark. 2003). Günümüzde endüstride çelik ve plastik gibi pek çok malzeme bulunmasına rağmen, halen daha en fazla talep edilen hammaddenin on bin kadar kullanım alanı ile odun olmasından kaynaklanabilir (Örs 2001). Ormancılık sektörünün ana gelir kaynağı olan odun hammaddesi üretiminde piyasa talebinin karşılanması ve yüksek gelir sağlanmasında üretilen odunun miktarı kadar odunun vasfı ve kalitesi de etkilidir. Tomrukların kalite sınıfları (ı. sınıf, II. sınıf ve III. sınıf); tomruğun boyutları ve üzerindeki görsel bozukluklara bağlı olarak belirlenir (Carpenter ve ark. 1989). Görsel kusurların yeri, tipi ve ebadı, tomruğun potansiyel kalite derecesinin yanı sıra değerini de belirlemede etkilidir (Wang ve ark. 2018).

Türkiye'de Orman Genel Müdürlüğü tarafından yılda yaklaşık 15.52 milyon $\mathrm{m}^{3}$ endüstriyel ve 4359646 ster yakacak odun üretilmektedir. Bu odunların satışından yılda 3 milyar 25 milyon 550 bin TL/yıl gelir elde etmektedir (OGM 2018). Tüketilen odun miktarı ise 29-30 milyon $\mathrm{m}^{3} / \mathrm{y}$ Il olup arz ve talep arasındaki açık yurt dışından odun ithal edilerek kapatılmaktadır. Bunun 500 - 600 bin $\mathrm{m}^{3}$ civarı sektörün I. ve II. sınıf kalitedeki odun ihtiyacının karşılanması amaçı yapılmaktadır. Türkiye ormanlarındaki odun hammaddesinin $10 \%$ 'u I. sınıf, 5.0\%'i II. sınıf ve $85.0 \%$ 'i III. sınıf olarak belirlenmesine rağmen uygulamada $0.5 \% \mathrm{I}$. sınıf, $3.5 \% \mathrm{II}$. sınıf ve $95.0 \% \mathrm{III}$. sınıf gibi çok düşük kalitede tomruk alınabilmektedir. Üründe oluşan bu kalite kayıplarının ve toplumun intiyacını karşılayacak miktarda ya da vasıfta yeterli odun üretilememesinin ana nedenlerinden birisi, odun hammaddesinin bölmeden çıkarılması aşamasında gördüğü zararlardır (OGM 2016).

Türkiye'de orman yolu standartlarının yetersizliği, mekanizasyonun kısıtlı olması ve ormanların büyük bölümünün eğimli ya da engebeli yerlerde sıkışıp kalması nedenleriyle bütün ağaç ya da bütün gövde üretimi yapılamamakta olup genellikle tomruk üretim tekniği uygulanmaktadır. Tomrukların bölmeden çıkarılmasında ise neredeyse tamamen zemin üzerinde sürütme tekniği kullanılmaktadır. Kalın çaplı odunların bölmeden çıkarılmasında en yaygın olarak kullanılan yöntem zemin üzerinde kontrolsüz sürütmedir (Erdaş ve ark. 1993). Bu yöntemde eğimli alanlarda büyük oranlarda insan gücü, eğimin az olduğu alanlarda ise hayvan gücü ve az oranda da makine gücü kullanılmaktadır.

Türkiye'de eğimli ormanlarda yukarıdan aşağıya doğru bölmeden çıkarmada yeterli miktarda kar yağışı olan alanlarda ekonomik ya da çevresel açıdan gerekli görüldüğünde kış üretimi gerçekleştirilirken, diğer bölgelerde büyük oranda yaz üretimi gerçekleştirilmektedir. Yaz mevsiminde tomruklar yukarıdan aşağıya doğru toprak zemin üzerinde kaydırılırken kış mevsiminde kar tabakası üzerinde kaydırılarak yol kenarına indirilirler.

Ağır olan odun hammaddesinin zemin üzerinde kontrolsüz olarak sürütülmesi sırasında odunların ağaçlara, fidanlara ya da taşlara çarpması ya da zemin ile arasındaki sürtünme nedeniyle çeşitli zararlar meydana gelebilmektedir. Yapılan pek çok çalışmada odun üretimi sırasında kesme-devirme (Jourgholami ve Abari 2017; Wang ve ark. 2004), yöresel yöntemler (Egan 1999; Vanderberg 2002; Ünver 2008) ya da mekanizasyon araçlarıyla (Gerasimov ve Seliverstov 2010; Nuutinen ve ark. 2010; Spinelli ve ark. 2010; Jonsson ve Hannrup 2007; Brunberg ve ark. 2006) bölmeden çıkarma faaliyetleri sırasında tomruklarda önemli fiziksel zararlar meydana geldiği ve bunlara bağlı olarak kalite, hacim ya da değer kayıplarının oluştuğu tespit edilmiştir.

Williston (1979) kırılma ve sürütme zararları nedeniyle hasat edilen tomruklarda yaklaşık \%6 oranında değer kaybı oluştuğunu belirlemiştir. Gürtan (1975) odun üretim faaliyetleri sırasında tomruklarda \%15-17 oranında miktar ve \%10 oranında kalite kayıpları oluştuğunu belirlemiştir. Ünver ve Acar (2008) yaz mevsiminde zemin üzerinde sürütme sırasında tomruklarda yaklaşık yaklaşık \%22 oranında miktar ve $\% 10$ oranında kalite kaybı oluştuğu belirlenmiştir. Tomruk gövdelerinde oluşan yaraların derinlik ve uzunluklarına göre yapılan değerlendirmede yaraların \%41'inin II. sınıf ve \%23'ünün ise III. sınıf yaralar oldukları belirlenmiştir. Wang ve ark. (2004) ise odun üretim sahalarında belirlenen tomrukların yaklaşık \%6'sının zarar gördüğü ve bunun sonucunda üretilen odunlarda \%6.7'nin üzerinde hacim ve değer kayıpları meydana geldiği belirlenmiştir. Ünver ve Acar (2009), sürütülen tomruğu etkileyen 
sürtünme vektörünü, tomruğun sürtünen yüzey alanını ve sürütme mesafesi parametrelerini dikkate alarak bir zarar tahmin modeli geliştirmiştir.

Bu çalışmada Doğu Karadeniz Bölgesindeki doğu ladini [Picea orientalis L. (Link)] ormanlarında iki farklı üretim mevsiminde (yaz ve kış) zemin üzerinde kontrolsüz sürütme sırasında tomruklarda oluşan hacim ve kalite kayıplarının belirlenmesi ve karşılaştııılması amaçlanmıştır.

\section{MATERYAL VE YÖNTEM}

Çalışma; Türkiye'nin Doğu Karadeniz bölgesindeki Trabzon ili yakınlarında, Greenwich'e göre $39^{\circ} 37^{\prime} 0,6^{\prime \prime}$ $39^{\circ} 45^{\prime} 00^{\prime \prime}$ doğu boylamları, Ekvatora göre $40^{\circ} 48^{\prime} 42^{\prime \prime}$ $40^{\circ} 52^{\prime} 00^{\prime \prime}$ kuzey enlemleri arasındaki ormanlarda gerçekleştirilmiştir (Şekil 1).

$\mathrm{Bu}$ bölgede yıllık ortalama sıcaklık $13{ }^{\circ} \mathrm{C}$ olup sıcaklık ortalaması en yüksek Ağustos $\left(21.8^{\circ} \mathrm{C}\right)$ ve en düşük Ocak $\left(4.4^{\circ} \mathrm{C}\right)$ ayında gerçekleşmektedir. Yıllık ortalama yağış miktarı 771.0 mm olup en yüksek yağış Ekim $(97 \mathrm{~mm})$ ve en düşük yağış Temmuz (34 $\mathrm{mm})$ ayında gerçekleşmektedir (URL-1, 2018). Çalışma alanları, yamaç aşağı zemin üzerinde kontrolsüz kaydırma yapılan ve ana ağaç türü doğu ladini [Picea orientalis (L.) Link.] olan meşcereler arasından seçilmiştir. Sürütülen odunda meydana gelen zararların belirlendiği bu çalışma yarısı yaz mevsiminde ve yarısı kış mevsiminde odun üretimi gerçekleştirilen hasat birimleri arasından seçilen toplam 16 alanda gerçekleştirilmiştir (Çizelge 1).

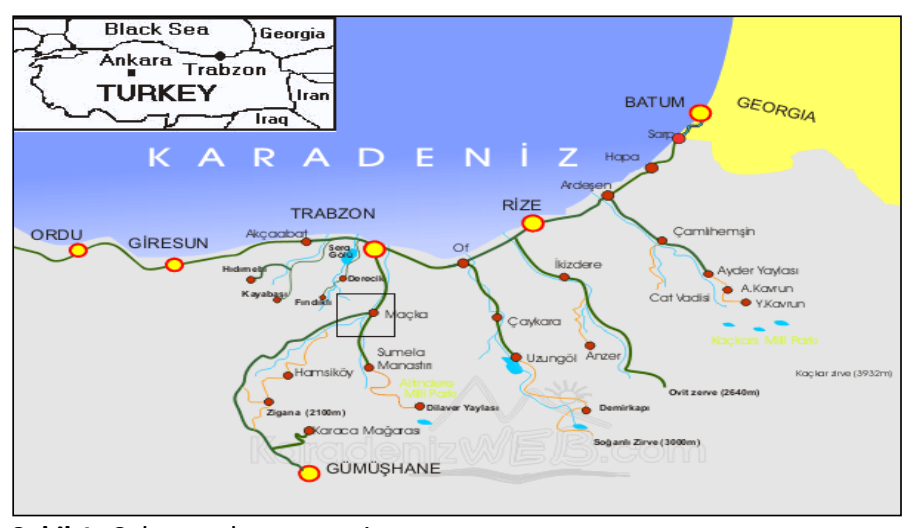

Şekil 1. Çalışma alanının yeri

Çizelge 1. Hasat birimlerinin genel özellikleri

\begin{tabular}{|c|c|c|c|c|c|c|}
\hline Hasat Mevsimi & Hasat Birimi & Alan (ha) & $\operatorname{Hacim}\left(m^{3}\right)$ & Ortalama Eğim (\%) & Kapalılık & Yaş (yıl) \\
\hline \multirow{12}{*}{ 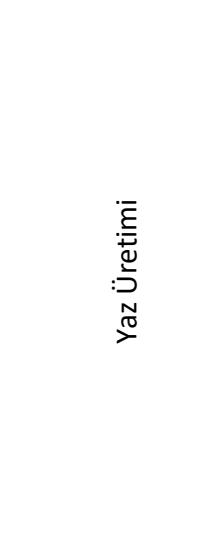 } & S-I & 24.9 & 174 & 60 & 3 & $48-65$ \\
\hline & S-II & 26.8 & 268 & 70 & 3 & $50-70$ \\
\hline & S-III & 27.3 & 273 & 45 & 3 & $50-70$ \\
\hline & S-IV & 44.5 & 516 & 45 & 2 & $65-85$ \\
\hline & $S-V$ & 23.2 & 536 & 80 & 3 & 80 \\
\hline & S-VI & 15.5 & 532 & 80 & 3 & 95 \\
\hline & S-VII & 3.8 & 208 & 65 & 3 & $90-110$ \\
\hline & S-VIII & 14.1 & 269 & 75 & 3 & $90-110$ \\
\hline & W-I & 12.6 & 1246 & 70 & 3 & 100 \\
\hline & W-II & 6.7 & 201 & 65 & 3 & 90 \\
\hline & W-III & 21.2 & 636 & 65 & 3 & 90 \\
\hline & W-IV & 15.9 & 550 & 70 & 3 & 110 \\
\hline \multirow{4}{*}{ 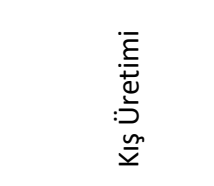 } & W-V & 7.5 & 128 & 72 & 2 & 80 \\
\hline & W-VI & 14.6 & 227 & 70 & 3 & $85-95$ \\
\hline & W-VII & 17.0 & 233 & 65 & 3 & $85-95$ \\
\hline & W-VIII & 12.5 & 255 & 80 & 2 & 54 \\
\hline
\end{tabular}

Sürütmeden önce ve sonra taşınacak her bir tomruğun kumpas ile çapları ve şerit metre ile boyları ölçülmüş ve Günay (1982)'nin tomruk değerlendirme kriterleri kullanılarak kalite sınıfları belirlemiştir (Çizelge 2).
Zemin üzerinde sürütülerek/kaydırılarak yol kenarına getirilen tomruklar üzerinde; meydana gelen zararların tipleri, boyutları ve yeri (uç, gövde) belirlenmiştir. Zarar tipleri; kırık, saçaklanma, yaralanma ve parçalanma olarak değerlendirilmiştir (Şekil 2). 
Çizelge 2. Tomruk değerlendirme kriterleri

\begin{tabular}{|c|c|c|c|}
\hline \multirow{2}{*}{ KUSURLAR } & \multicolumn{3}{|c|}{ KALITE SINIFLARI } \\
\hline & 1 & II & III \\
\hline Çürük ve Kovuk (Tomruk başı) & $<\% 5$ & $\% 5-10$ & $\% 10-20$ \\
\hline \multicolumn{4}{|l|}{ Budaklar } \\
\hline Sağlam Çapı & $3-10 \mathrm{~cm}$ & $11-15 \mathrm{~cm}$ & $>15 \mathrm{~cm}$ \\
\hline Çapların Toplamı; & $<15 \mathrm{~cm}$ & $15-30 \mathrm{~cm}$ & $<60 \mathrm{~cm}$ \\
\hline Çürük ve Özürlü & Bulunmaz & $<10 \mathrm{~cm}$ & $10-20 \mathrm{~cm}$ \\
\hline Sağlam, çürük ve özürlü budak & Sağlam; Çapı 3-10 cm & Çapları toplamı $<12 \mathrm{~cm}$ & $12-25 \mathrm{~cm}$ \\
\hline \multicolumn{4}{|l|}{ Çatlaklar } \\
\hline Uzunluğunun tomruk boyuna oranı & $<\% 20$ & $\% 20-50$ & $\% 50<$ \\
\hline Derinliğinin tomruk çapına oranı & $<\% 20$ & $\% 20-50$ & Çap kadar \\
\hline \multicolumn{4}{|l|}{ Yaralar } \\
\hline Tomruk çapının yara derinliğine oranı & $<\% 5$ & $\% 5-10$ & $\% 10-20$ \\
\hline Tomruk boyunun yara boyuna oranı & $<\% 10$ & $\% 10-20$ & $\% 20-50$ \\
\hline Kapalı yaralar & Yok & Olası & Olası \\
\hline
\end{tabular}

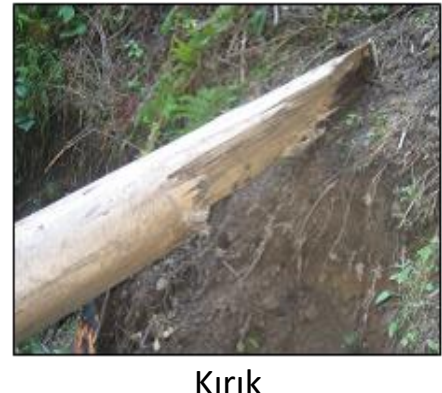

Kırık

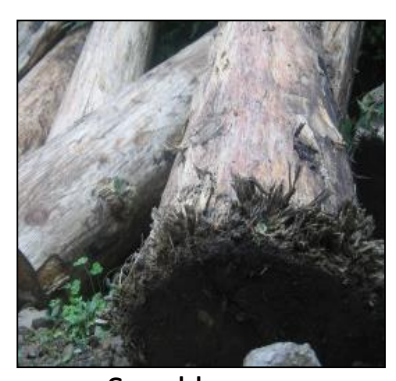

Saçaklanma

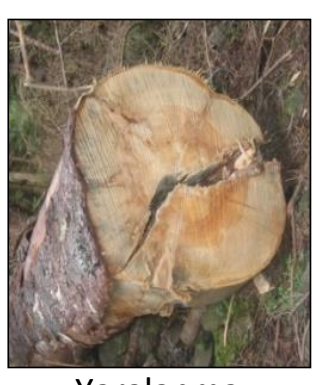

Yaralanma

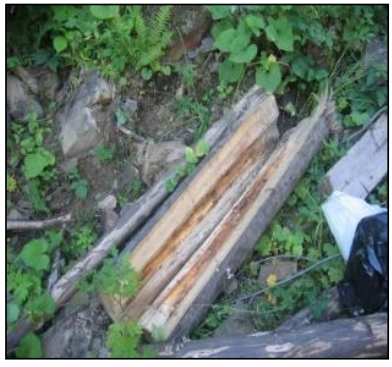

Parçalanma

Şekil 2. Odunlarda oluşan zarar tipleri

Sürütülen/kaydırılan tomrukların hacimleri (V) Huber hacim formülü ile hesaplanmıştır (Castellanos, 2007).

$\mathrm{V}=\frac{\pi}{4} * d^{2} * l$

Burada; $d$; tomruğun orta çapını (m), l; tomruğun boyunu (m) ve $\pi$, sabit sayı (3.14) ifade etmektedir. Yol kenarına getirilen tomruklar, kamyona yüklenmeden önce zarar görmüş kısımları kesilerek silindirik şekle getirilir. Kesilen parçaların çap ve boyları ölçülüp hacimleri hesaplanarak tomrukta oluşan hacim kayıpları belirlenmiştir.

Üretim mevsimine göre tomruklarda oluşan tomruklarda oluşan hacim kayıpları, tomruk vasfındaki ve kalite sınıflarındaki değişimler dikkate alınmıştır. İstatistiksel değerlendirmeler SPSS $^{\circledR} 13.0$ for Windows $^{\circledR}$ paket programı kullanılarak gerçekleştirilmiştir.

\section{BULGULAR VE TARTIŞMA}

Araştırma kapsamında yaz ve kış üretimi yapılan hasat birimlerinde zemin üzerinde sürütülen tomrukların sürütme öncesi ve sonrasındaki ortalama çap $(\mathrm{cm})$, boy $(\mathrm{m})$, hacim $\left(\mathrm{m}^{3}\right)$, zarar gören kısımların boyutları $(\mathrm{m})$ ve oluşan hacim kaybı miktarları (\%) belirlenmiştir (Çizelge 3).

Çizelge $3^{\prime}$ te görüldüğü gibi zemin üzerinde sürütme/kaydırma sonucu yaz mevsiminde bölmeden çıkarılan odunlarda oluşan miktar kaybı, kış mevsimindekinin yaklaşık iki katıdır. Bunun nedenleri Wang ve ark. (2004)'ın da belirttiği gibi, yaz mevsiminde sürütülen odun ile toprak zemin arasındaki sürtünme katsayısının yüksek olması, zeminin pürüzlülüğü ve odunun sürütme güzergahlarında bulunan üretim kalıntıları, taşlara ya da çevresindeki ağaçlara/fidanlara çarpması olabilir. 
Çizelge 3. Üretim mevsimine göre sürütülen odunlarda meydana gelen miktar kayıpları

\begin{tabular}{lcc}
\hline & Kış Mevsimi & Yaz Mevsimi \\
\hline $\begin{array}{l}\text { Zarar görmüş } \\
\text { (adet) }\end{array}$ & 132 & 186 \\
$\begin{array}{l}\text { Ortalama çap (cm) } \\
\text { Ortalama boy (m) }\end{array}$ & 36.0 & 32.0 \\
$\begin{array}{l}\text { Odun hacmi (m³/adet) } \\
\text { Sürütme öncesi toplam }\end{array}$ & 2148.68 & 3.20 \\
hacim (m ${ }^{3}$ ) & 0.45 & 0.35 \\
Sürütme sonrası toplam & 1535.60 & 3258.45 \\
hacim (m ${ }^{3}$ ) & & 1704.75 \\
Hacim Kaybı (\%) & 28.50 & 47.70 \\
\hline
\end{tabular}

Kaydırılan odunların çapları $4 \mathrm{~cm}$ aralıklı çap sınıflarına ayrılmış ve her iki mevsimde üretilen odunların çap sınıflarına dağılımları belirlenmiştir (Şekil 3). Şekil 3'te görüldüğü gibi çapı 36 cm'nin üzerinde olan odun miktarı kış üretim mevsiminde yaz üretim mevsimindekinin yaklaşık 1.6 katıdır. Bu durum kar tabakası üzerinde kaydırmanın iş kolaylığı sağlaması bakımından sürütülmesi zor olan kalın çaplı odunların üretileceği alanlarda kış üretiminin tercih edilmesinden kaynaklanmış olabilir.

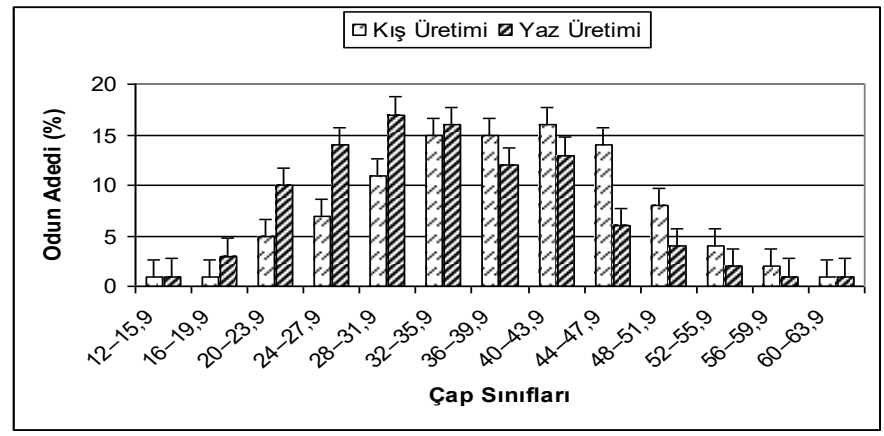

Şekil 3. Sürütülen odunların çap sınıflarına dağılımı

Araştırma kapsamında incelenen kış ve yaz üretimi yapılmış hasat birimlerinde sırasıyla toplam $1535,595 \mathrm{~m}^{3}$ ve $1704,749 \mathrm{~m}^{3}$ odun hasat edilmiştir. Her iki üretim mevsiminde de daha çok; tomruk, kağıtlık odun, maden direk ve sanayi odun vasfında odun üretilmiştir (Çizelge 4). Çizelge 4'te görüldüğü gibi kış mevsiminde üretilen odunların vasıfları daha çok tomruk (\%70) ve maden direk (\%14) iken; yaz mevsiminde üretilenler ise kış mevsimindekinden daha az miktarda tomruk (\%58) ve kağıtlık odun (\%36) olduğu belirlenmiştir.

Çizelge 4. Üretim mevsimine göre üretilen endüstriyel odun vasıflarının miktarları

\begin{tabular}{lcccc}
\hline Ürün Tipi & \multicolumn{2}{c}{ Sürütme Öncesi } & \multicolumn{2}{c}{ Sürütme Sonrası } \\
\cline { 2 - 5 } & Kış Mevsimi & Yaz Mevsimi & Kış Mevsimi & Yaz Mevsimi \\
\hline & $(\%)$ & $(\%)$ & $(\%)$ & $(\%)$ \\
Tomruk & 70 & 58 & 62 & 41 \\
Maden Direk & 14 & 4 & 9 & 7 \\
Sanayi Odunu & 5 & 2 & 6 & 6 \\
Kağıtlık Odun & 11 & 36 & 9 & 18 \\
Yakacak Odun & - & - & 14 & 28 \\
\hline
\end{tabular}

Her iki üretim mevsiminde de üretim faaliyetlerinden sonra odunlarda kırılma, saçaklanma, yaralanma ve tamamen parçalanma zararları belirlenmiştir (Şekil 4). Şekil 4'te görüldüğü gibi zemin üzerinde sürütme/kaydırma sonucu odunlarda en yaygın oluşan zarar tipleri; kış mevsiminde kırılma ve yaralanma iken yaz mevsiminde kırılma ve saçaklanmadır. Tamamen parçalanarak yakacak oduna dönüşen odun miktarı ise yaz mevsiminde kış mevsimindekinin yaklaşık iki katıdır. Benzer olarak Erdaş ve ark. (2015) kış üretiminde üretim kayıplarının yaz üretimine oranla daha düşük seviyede olduğunu belirlemişlerdir.

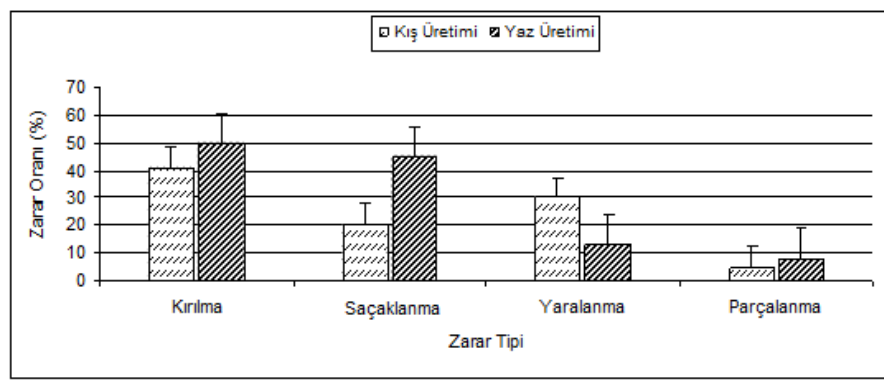

Şekil 4. Üretim mevsimine göre odunda oluşan zarar tiplerinin oransal dağııımı

Şekil 5 incelendiğinde, uzun boylu odunların hem uç hem de gövde kısmında kış mevsiminde yaz mevsimine oranla daha küçük düzeyli ama daha çok sayıda zararlar oluştuğu belirlenmiştir. Yaz mevsiminde sürütülen odun ile toprak zemin arasındaki sürtünme kaynaklı oluşan iş güçlüğü nedeniyle büyük oranda kısa boy tomruk üretimi tercih 
edilmektedir. Kış mevsiminde sürütme işinin toprak zeminin olumsuzluklarını örten kar zemin üzerinde gerçekleştirilmesi nedeniyle uzun boy odun üretimi yapılabilmektedir. Bu durum aralama kesimi uygulanan kış üretim sahalarında kontrolü zor olan uzun odunların meşcerede kalan ağaçlara sürtünmeleri, çarpmaları ya da ağaçlara takılmalarının fazlaca gerçekleşmesinden kaynaklanmış olabilir. Her iki üretim mevsiminde de odunda oluşan zararın yerine göre zarar görmüş bölgenin boyutunun dağııımları belirlenmiştir (Şekil 6).

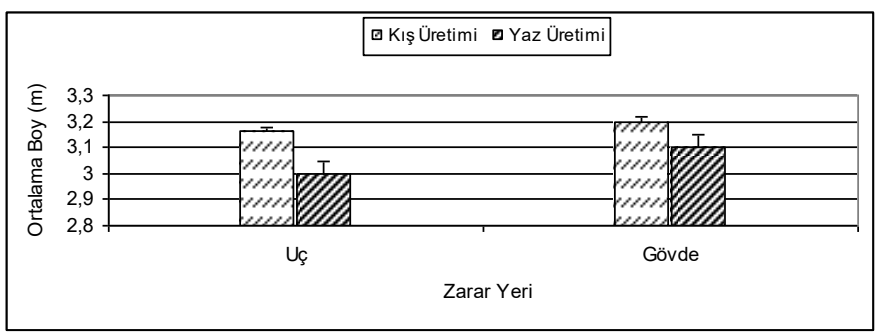

Şekil 5. Sürütülen odunların ortalama boyları ve zarar yeri değişimi

Şekil 6'da görüldüğü gibi kış mevsiminde odunun uç ve gövde kısımlarında zarar görmüş kısımların ortalama uzunlukları sırasıyla $33 \mathrm{~cm}$ ve $26 \mathrm{~cm}$ iken yaz mevsiminde sırasıyla $51 \mathrm{~cm}$ ve $36 \mathrm{~cm}$ 'dir. Her iki üretim mevsiminde de Behjou (2013)'nun çalışması ile benzer olarak odunların uç kısımlarında gövde kısmına oranla daha fazla zarar meydana gelmiştir. Bu durum, odunlarda darbeye en fazla uç kısımlarının maruz kalmasından kaynaklanmıştır.

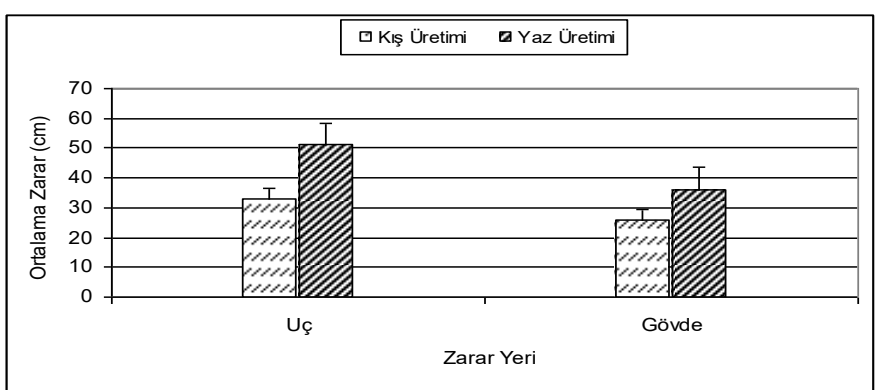

Şekil 6. Sürütülen odunlarda zararın yerine göre ortalama zarar miktarları

Her iki üretim mevsiminde de sürütülen odunda en fazla oluşan zarar tipi FAO (1998)'nun raporunda da belirtildiği gibi uç kısımlarda kırılma olarak meydana gelmiştir.
Odunlarda kırıldığı ya da saçaklandığı için kesilen kısımların ortalama uzunlukları, yaz mevsiminde sırasıyla $40 \mathrm{~cm}$ ve $28 \mathrm{~cm}$ iken kış mevsiminde $36 \mathrm{~cm}$ ve $18 \mathrm{~cm}$ 'dir. Odunlarda kırılma, yaz mevsiminde kış mevsimindekinden daha fazla gerçekleşmesine rağmen kırıklıkların ortalama uzunlukları her iki üretim mevsiminde de yaklaşık aynıdır. Yaz mevsiminde odunlarda oluşan saçaklanma miktarı kış mevsimindekinin yaklaşık 2 katı olmasına rağmen ortalama saçaklanma uzunlukları yaklaşık 1.5 katı gerçekleşmiştir. $\mathrm{Bu}$ durum odunların kar tabakası üzerinde yüksek eğim ve düşük sürtünme kuvveti etkisiyle hızlı kayarken kalan ağaçlara ve engellere sert şekilde çarparak uzun kırılmalar ve yaralanmalara maruz kalmasından kaynaklanmış olabilir. Yaz mevsiminde yapılan sürütme faaliyetlerinde ise odundaki zararlar, kayma hızının düşük, sürtünme kuvveti ve zemin pürüzlüğünün ise yüksek olması nedeniyle meydana gelmiş olabilir.

Çalışma kapsamında yaz ve kış mevsimlerinde yapılan üretim çalışmalarında zarar görmüş 318 tomrukta çap, boy, hacim, zarar yeri, zarar tipi ve zarar miktarı verilerine normal dağılım testi uygulanmıştır. Analiz sonucunda verilerin çarpıklık değerinin 0.419 ile 0.355 arasında ve basıklık değerinin 0.211 ile 0.178 arasında değiştiği belirlenmiştir. Tabachnick ve Fidell (2013)'in belirttikleri gibi çarpıkıı ve basıklık değerlerinin 1.5 ile-1.5 arasında olmaları nedeniyle veriler normal dağılım göstermektedirler.

Normal dağıldığı belirlenen verilerde üretim mevsimine göre zarar yeri, zarar tipi, zarar miktarı, odunun boyutları ve hacmi arasında anlamlı bir farklılık olup olmadığını belirlemek için bağımsız örneklem $t$ testi uygulanmıştır. Çizelge 5 'te görüldüğü gibi zarar yeri, zarar tipi ve odun boyunun hasat mevsimine göre $\% 95$ güven düzeyinde $(P<0.05)$ anlamlı bir farklılık gösterdiği diğerlerinde fark olmadığı belirlenmiştir. 
Çizelge 5. Hasat mevsimine göre zarar yeri, zarar tipi ve odun boyu farklılıkları

\begin{tabular}{cccccc}
\hline & Ortalama & Standart sapma & $\mathrm{t}$ & $\mathrm{df}$ & $\mathrm{p}(2$-yön) \\
\hline Zarar Yeri & 2.0833 & .27744 & 3.198 & 316.000 & .002 \\
& 1.9409 & .45530 & 3.458 & 309.559 & .001 \\
Zarar Tipi & 1.4242 & .86599 & -3.470 & 316.000 & .001 \\
Odun Boyu & 1.7849 & .94554 & -3.522 & 296.267 & .000 \\
& 3.0795 & .23565 & -2.028 & 316.000 & .043 \\
\hline
\end{tabular}

Sürütülen odunun meşcerede kalan ağaçlara takılması, orman içerisinde taşınamayacağı yerlere ya da yükleme

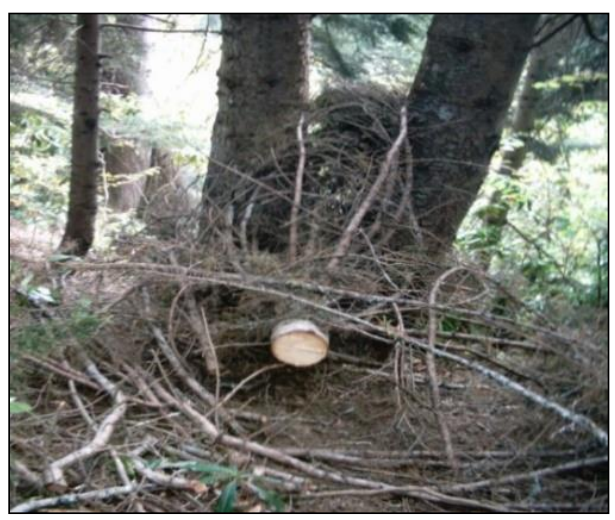

Şekil 7. Taşınamayarak ormanda kalan ağaçlar

Taşınamayarak ormanda kalan tomruklar nedeniyle oluşan miktar kaybı, kış mevsiminde \%0.6 iken yaz mevsiminde \%1.5 olarak gerçekleşmiştir. Bu durumun, zor arazi koşulları, meşcerenin sıklığı, diri örtü miktarı, yanlış sürütme güzergahının kullanımı, kontrolün kaybedilmesi ya da iş̧̧i hataları sonucu meydana gelmiştir.

Çalışma alanlarında sürütmeden önce ürünlerin kalite sınıfları \%5'i 2 . sınıf ve \%95'i 3 . sınıf olarak belirlenmişken sürütmeden sonra 2. sınıf ürünlerin tamamına yakınının sürütme sırasında uğradıkları zararlar sonucu 3. sınıfa düştükleri belirlenmiştir. Bu durum Carmean ve Boyce (1974)'nin belirttiği gibi odunların zarar gören uç kısımlarının kesilmesi nedeniyle odunun boyutlarında oluşan değişim ve darbe ya da sürtünme kaynaklı olarak gövde üzerinde oluşan kusurlardan kaynaklanmıştır.

\section{SONUÇLAR}

Zemin üzerinde kaydırma sonucu odunlarda yaz mevsiminde kış mevsimine oranla yaklaşık \%20 daha fazla miktar kaybı oluştuğu belirlenmiştir. Kış mevsiminde genelde sürütülen odunun uç kısımlarda kırılma ve gövde rampasının bulunduğu yolun aşağısına yuvarlanması sonucu ormanda kalabilmektedir (Şekil 7).

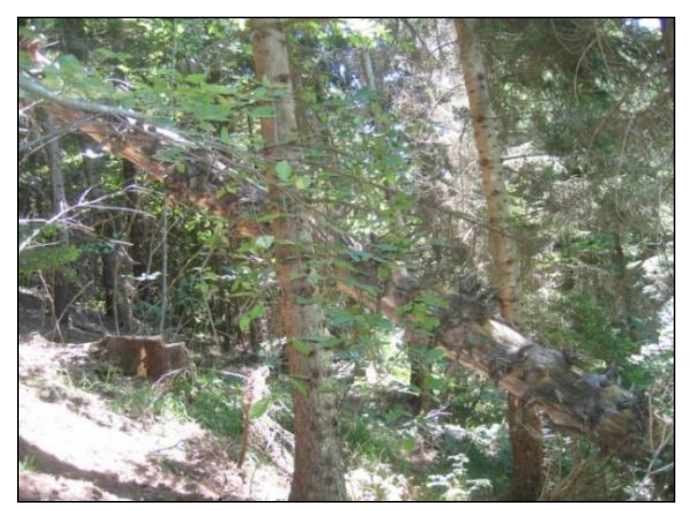

üzerinde yaralanma, yaz mevsiminde ise uç kısımlarda kırılma ve saçaklanma meydana gelmiştir. Her iki üretim mevsiminde de odunların uç kısımlarında gövde kısımlarına oranla daha fazla zarar meydana gelmiştir. Yaz mevsiminde odunun hem uç hem de gövde kısımlarında oluşan zararların boyutları kış mevsimindekinden daha fazladır. Çıkarılamadan ormanda kalan odunlar nedeniyle oluşan miktar kaybı ise kış mevsiminde yaz mevsimindekilerin yaklaşık 2.5 katı daha fazladır.

Kış mevsiminde üretilen odunların vasıfları, çoğunlukla birim fiyatı fazla olan tomruk ve maden direk iken; yaz mevsiminde kış mevsimine oranla daha az miktarda tomruk ve kağıtlık odundur. Sürütülen odunda oluşan zararların tipi ve zararın yeri arasında üretim mevsimine göre \%95 güven düzeyinde farklılık belirlenmiştir. Her iki üretim mevsiminde de kalite sınıfı 2 . sınıf olarak belirlenen ürünlerin tamamı gördükleri zararlar sonucunda 3. kalite sınıfına düşmüşlerdir.

- Sürütülen odunların uç kısımlarında oluşan zararı azaltmak, parça kesilmesi sonucu oluşacak miktar kaybı ve vasıf değişimlerini engellemek için odunlara tomruk konileri takılabilir. 
- Odunlarda oluşan miktar kaybı, vasıf değişimi ve görsel kusurlar; çalışma alanının özellikleri ve üretim mevsimine göre doğru tekniklerin kullanımı, iyi planlama yapılması ve deneyimli ya da eğitimli orman işçilerinin çalıştırılması ile azaltılabilir.

- Uzun boylu ya da kalın çaplı tomrukların üretileceği alanlarda kış mevsiminde üretim yapılması daha uygun olabilir.

- Özellikle yaz mevsiminde zeminin kötü olduğu alanlarda kalın çaplı ürünlerin taşınmasında havai sistemler, kablo çekimi ya da kontrollü sürütme gibi yöntemlerin kullanılması tercih edilebilir.

Orman içerisinde uygun yerlere polietilen gibi kaygan malzemeden yapılan basit ve portatif yapay güzergahlar kurularak motor gücü (el vinci, traktör gibi) ya da basit makara sistemleri ile kontrollü kaydırma gerçekleştirilebilir. Böylece az bir masrafla tomrukların toprakla teması kesilebilir ve tomrukların çevresindeki ağaç, fidan ya da kaya gibi malzemelere çarpma sonucu görebileceği zararlar engellenmiş olabilecektir.

\section{TEŞEKKÜR}

Bu çalışma, Karadeniz Teknik Üniversitesi Bilimsel Araştırma Projeleri Birimi (KTÜ-BAP) tarafından 113-0016 nolu proje ile desteklenmiştir.

\section{KAYNAKLAR}

Acar HH, Ünver S, Kaplan E (2007) Mevcut orman yollarının puanlandırılması ve değerlendirilmesi. Orman Mühendisleri Odası Yayın Organı 45(4-5-6): 31-34.

Behjou FK (2013) Economic analysis on log damage during logging operation in Caspian forests. Journal of Forestry Research 24(3): 585-589.

Brunberg T, Hofsten H, Jonsson M (2006) Study damage to logs research and evaluation. Skogsforsk Resultat 18: $4 \mathrm{p}$.

Carmean WH, Boyce SG (1974) Hardwood log quality in relation to site quality, north central forest experiment station forest service. U.S. Department of Agriculture, $7 \mathrm{~s}$.

Carpenter RD, Sonderman DL, Rast ED (1989) Defects in hardwood timber. Agricultural Handbook No. 678. U.S. Department of Agriculture, Forest Service, Washington, DC.

Castellanos, A, Blanco AM, Palencia V (2007) Applications of radial basis neural networks for area forest. International Journal Information Theories \& Applications 14 (1): 218-222.

Egan AF (1999) Residual stand damage after shovel logging and conventional ground skidding in an Appalachian hardwood stand. Forest Products Journal 49(6): 88-92.

Erdaş O, Acar HH (1993) Türkiye'de odun hammaddesi üretimi özellikle kesim, bölmeden çıkarma ve taşıma sırasında karşılaşılan güçlükler ve bunların orman ürünleri endüstrisi üzerine etkileri. II. Ulusal Orman Ürünleri Endüstrisi Kongresi. Trabzon.
Erdaş O, Akay AE, Büyüksakallı H, Şakar D (2015) Kış üretimi çalışmalarının değerlendirilmesi: Andırın-Kahramanmaraş örneği. Üretim İşlerinde Hassas Ormancılık Kongresi. 4-6 Haziran, IlgazTürkiye. 181-192.

Food and Agriculture Organization (FAO) (1998) Forest harvesting operations in papua new guinea the PNG logging code of practice. Forest Harvesting Case-Studies-15, Rome.

Gerasimov Y, Seliverstov A (2010) Industrial round-wood losses associated with harvesting systems in Russia. Croatian Journal of Forest Engineering 31 (2): 111-126.

Günay Z (1982) Orman ürünleri standardizasyonu ve kübaj. Saydam Matbaacılık Ofset -185309. Ankara.

Gürtan H (1975) Dağlık ve sarp arazili ormanlarda kesim ve bölmeden çıkarma işlerinde uğranılan kayıpların saptanması ve bu işlemlerin rasyonalizasyonu üzerine araştırmalar. Tübitak Yayınları 250. Ankara.

Jonsson P, Hannrup B (2007) Timber-value tests 2006 - timber damage and defects. Skogsforsk Resultat (7): 4 p.

Jourgholami M, Abari ME (2017) Log damage and value loss following motor-manual tree harvesting in the Hyrcanian forest, Northern Iran. Eur J Forest Eng. 3(1): 35-43.

Kazancıoğlu H (2003). Orman ürünleri endüstrisine giriş. Karadeniz Teknik Üniversitesi Orman Fakültesi Yayınları 73, Trabzon.

Marshall HD, Murphy GE, Boston K (2006) Evaluation of the economic Impacts of length and diameter measurement error on mechanical processors and harvesters operating in pine stands. Canadian Journal of Forest Research 36: 1661- 1673.

Murphy G, Twaddle AA (1985) Techniques for the assessment and control of log value recovery in the New Zealand forest harvesting industry. In: Proceedings of the 9th Annual Meeting of Council on Forest Engineering. Mobile. Al.

Nuutinen Y, Väätäinen K, Asikainen A, Prinz R, Heinonen J (2010) Operational efficiency and damage to sawlogs by feed rollers of the harvester head. Silva Fennica 44(1): 121-139.

Orman Genel Müdürlüğü (OGM) (2018) Orman Genel Müdürlüğü 2017 yılı faaliyet raporu. Strateji dairesi başkanlığı, Ankara.

Orman Genel Müdürlüğü (OGM) (2016) Oduna dayalı orman ürünlerinin üretim ve pazarlama faaliyetleri. OGM iş̧letme ve Pazarlama Dairesi Başkanlığı, Ankara.

Örs Y, Keskin H (2001) Ağaç malzeme bilgisi. T.C. Sanayi ve Ticaret Bakanlığı Küçük ve Orta Ölçekli Sanayi Geliştirme ve Destekleme İdaresi Başkanlığı, Kale Matbaacııık Ofset, Ankara.

Özçelik R (2002) Tomruk hacminin tahmininde kullanılan centroid metodu ve dört standart formülün karşılaştırılması. Süleyman Demirel Üniversitesi Orman Fakültesi Dergisi. A/1: 115-120.

Spinelli R, Magagnotti N, Nati C (2010) Comparison between mechanised and manual log-making in Italian poplar plantations. FORMEC 2010 Forest Engineering: Meeting the Needs of the Society and the Environment, 11-14 July. Padova - Italy, 8p.

Tabachnick BG, Fidell LS (2013) Using multivariate statistics. Boston, Pearson.

URL-1, 2018. Climate: Maçka - Climate Graph, Temperature Graph, Climate Chart. Climate-Data.org. https://tr.climatedata.org/location/8552.

Ünver S (2008) Endüstriyel odun hammaddesinin insan gücüyle sürütülmesi sırasında ortaya çıkan ürün kayıpları ile çevresel zararların belirlenmesi üzerine bir araştırma. Karadeniz Teknik Üniversitesi Fen Bilimleri Enstitüsü, Trabzon.

Ünver S, Acar HH (2009) A damage prediction model for quantity loss of skidded spruce logs during ground base skidding in North Eastern Turkey. Croatian Journal of Forest Engineering 30(1): 5965. 
Ünver S, Acar HH (2008) An investigation on impacts of ground-based skidding techniques to transported wood material. International Seminar on Infrastructure and Transport in Sustainably Managed Forests, 21-26 October. Portorož, Slovenia.

Vanderberg MR (2002) Harvested log damage and value loss associated with two ground-based harvesting systems in Central Appalachia. Master of Science. Davis College of Agriculture, Forestry, and Consumer Sciences at West Virginia University. 90p.

Wang X, Thomas E, Xu F, Liu Y, Brashaw BK, Ross R (2018) Defect detection and quality assessment of hardwood logs: part 2- combıned acoustic and laser scanning system. Wood and Fiber Science 50(3): 310-322.

Wang J, LeDoux CB, Vanderberg M, McNeel J (2004) Log damage and value loss associated with two ground-based harvesting systems in Central Appalachia. International Journal of Forest Engineering 15(1): 61-69.

Williston E (1979) Opportunity areas and leverage points. In: Proceedings of the Electronics Workshop. Sawmill and Plywood Clinic. Portland-Oregon. 14-18. 